\title{
田
}

\section{DERECHOS HUMANOS Y TRABAJO SOCIAL: UNA TESIS EXPLICATIVA DE SU RELACIÓN}

\author{
Human rights and social work: an explanatory thesis of their relationship
}

Omar Santiago Herrera Rodríguez*

\section{RESUMEN}

En este trabajo examino la emergencia y desarrollo de la discusión sobre Derechos Humanos en el Trabajo Social latinoamericano durante la década de los ochenta, enfatizando en el caso costarricense; a partir del análisis de las condiciones socio-históricas de esa época y cómo éstas influyeron en la recepción de este tema en el gremio.

\section{PALABRAS CLAVE}

Derechos Humanos. Trabajo Social. Seguridad Nacional. Violencia. Ética.

\section{ABSTRACT}

In this paper I examine the emergence and development of the Human Rights discussion in the Latin American Social Work during the eighty's, emphasizing the Costa Rican case; from the analyses of the sociohistorical conditions of that time and how these influenced the reception of this topic in the guild.

\section{KEYWORDS}

Human rights. Social work. National security. Violence. Ethics.

Submissão: 27/9/2018.

Aceite: 26/11/2018.

\section{Introducción}

Este trabajo se dedica a demostrar la siguiente tesis: la emergencia y desarrollo de la discusión sobre Derechos Humanos en el Trabajo Social latinoamericano se produjo especialmente durante la década de los años ochenta, producto de los procesos de transición hacia regímenes electoralmente establecidos después de una época de implementación de regímenes de seguridad nacional por parte del gobierno estadounidense en acuerdo con sectores de las oligarquías nacionales y las cúpulas militares latinoamericanas.

\footnotetext{
* Docente e investigador de la Universidad de Costa Rica, Sede de Occidente. (UCR, San Ramon, Costa Rica). Alajuela Province, San Ramon, Costa Rica. ORC ID: <https://orcid.org/0000-0002-6717-2769>. E-mail: <omsahero@gmail.com>.
}

DOI 10.22422/temporalis.2018v18n36p139-161 
El proceso de implantación de regímenes dictatoriales que inició en 1964 en Brasil contra el gobierno de João Goulart y se extendió por casi todos los países de Suramérica durante la década de los setenta (obviando de forma consciente el caso aislado del golpe de Estado contra Jacobo Arbenz en Guatemala, 1954), generó un escenario crítico de violación sistemática de los derechos y libertades más fundamentales de la ciudadanía, así como un golpe directo para inhibir la capacidad de organización de ésta.

Agotada, por innecesaria, esta estrategia geopolítica del gobierno estadounidense en la región, se inició una fase de transición democrática (en el sentido liberal del concepto, es decir, restringida a la celebración de elecciones), que potenció el surgimiento de organizaciones, comisiones, fundaciones y comités dedicados al esclarecimiento de los crímenes cometidos en los años anteriores y la búsqueda de justicia. Derechos Humanos surge como núcleo condensador de las sensibilidades culturales de época y los horizontes de lucha política.

Debido a las características de los escenarios laborales de Trabajo Social y por la sensibilidad heredada en una parte del gremio gracias al Movimiento de Reconceptualización, Derechos Humanos es sumado como contenido de la profesión durante la década de los ochenta en los principales espacios de encuentro del gremio en América Latina, así como en los espacios formativos y regulativos (entiéndase carreras y colegios profesionales respectivamente) a nivel nacional. Esta es pues, la tesis que se pretende demostrar.

Por esta razón se plantean como objetivos de este trabajo: 1. Reconstruir las condiciones socio-históricas más importantes que posibilitaron en América Latina la discusión sobre Derechos Humanos, 2. Mostrar los vínculos presentes de las discusiones desarrolladas por una parte del gremio de Trabajo Social en América Latina acerca de Derechos Humanos con el clima socio-político de época, enfatizando en el caso costarricense para dar un ejemplo demostrativo de la tesis y 3. Examinar la forma (expresiones teóricas e ideológicas) en que Derechos Humanos fue comprendido por el gremio de Trabajo Social en los principales escenarios de discusión construidos en América Latina y específicamente en el caso costarricense mediante el análisis de documentación del Colegio de Trabajadores Sociales de Costa Rica (COLTRAS) y la Escuela de Trabajo Social de la Universidad de Costa Rica.

De esta manera, la primera parte de este trabajo expone un marco básico de las condiciones socio-históricas de posibilidad para la emergencia de la discusión sobre Derechos Humanos en América Latina, enfatizando en dos elementos de un mismo proceso histórico: la implementación del programa neoliberal y su necesidad de mecanismos de violencia y represión extremos para su institución en la región.

La segunda parte aborda el surgimiento y desarrollo de la discusión sobre Derechos Humanos en el Trabajo Social latinoamericano ${ }^{1}$, haciendo énfasis en dos escenarios de gran importancia para la profesión en este espacio: los Seminarios Latinoamericanos de Trabajo

\footnotetext{
${ }^{1}$ Por Trabajo Social latinoamericano hago una abstracción de los múltiples grupos, movimientos y posiciones que existen concretamente en los diferentes países de la también pluri-forme y compleja región latinoamericana; en este sentido, es una forma sencilla de hablar para dar cuenta de la existencia, gracias al Movimiento de Reconceptualización, de espacios de discusión y formación a nivel regional.
} 
Social y la producción de conocimiento divulgada a través de la revista Acción Crítica, por parte del Centro Latinoamericano de Trabajo Social (CELATS).

La tercera parte expande y profundiza los contenidos expuestos en el apartado anterior, centrándose ahora en cómo se entendió Derechos Humanos en la producción de conocimientos realizada por el Trabajo Social en América Latina; con lo cual se evidencian las discontinuidades presentes entre las razones o motivos históricos que propiciaron el surgimiento de la discusión en este tema y la manera (los marcos teóricos e ideológicos) en que, como gremio, fue comprendido Derechos Humanos.

Finalmente, la cuarta parte de este trabajo ofrece a los (as) lectores (as) un ejemplo local de recepción de la discusión de Derechos Humanos: el caso costarricense; con el fin evidenciar la aplicabilidad de la tesis que se ofrece aquí para estudiar la incorporación de Derechos Humanos como tema de relevancia en el Trabajo Social de la región.

\section{Emergencia de la discusión sobre Derechos Humanos en América Latina}

A pesar que la Declaración Universal de Derechos Humanos (DUDH) fue aprobada en 1948, acontecimiento que respondió a un clima político-cultural específico que permitió su viabilidad después de varios desencuentros y conflictos político-diplomáticos ${ }^{2}$ entre las principales potencias mundiales de ese momento; para América Latina la discusión e incorporación de Derechos Humanos como base reflexiva y horizonte de lucha comenzó cerca de dos décadas después, producto de las experiencias de los Estados de Seguridad Nacional en América del Sur y la Guerra de Baja Intensidad en Centroamérica financiadas por el gobierno estadounidense. En palabras de Hinkelammert (2012):

La estrategia de globalización en muchas partes se impuso a través del terrorismo del Estado, como en Chile, Argentina, Uruguay, en cierto grado Brasil, Colombia, y se repite en Centroamérica. La situación dramática que se produce lleva a la defensa de estos derechos humanos tocados directamente para la estrategia de globalización (HINKELAMMERT, 2012, p. 97-98).

Ciertamente, el neoliberalismo insertado en América Latina a través de los denominados Programas de Ajuste Estructural promovidos por el Fondo Monetario Internacional (FMI) y el Banco Mundial (BM) (como fue el caso centroamericano), o mediante la construcción de laboratorios, como los ha denominado Klein (2010), para la experimentación del ideario económico de la Escuela de Chicago (como fueron los casos de Chile, Argentina, Uruguay y ciertas partes de Brasil), conformaron un escenario crítico en toda la región que demandó el uso de medidas altamente represivas y violentas sobre la población.

Esto explica el por qué en menos de 15 años casi todos los países de América Latina, como lo muestran los estudios de Comblin (1988 y 1989) y Gallardo (1989), habían sufrido uno o varios golpes de Estado por parte de las cúpulas militares financiadas y entrenadas por los distintos gobiernos estadounidenses de turno a lo largo de las décadas de 1960 y 1970.

Las razones de estos acontecimientos se encuentran en la Estrategia de Seguridad Hemisférica, como señala Gallardo (1989), adoptada por el gobierno estadounidense para

\footnotetext{
${ }^{2}$ Ver el trabajo de Beitz (2012).
} 


\section{tempordilis}

responder de forma inmediata a la Revolución Cubana de 1959 y para prevenir el surgimiento de nuevos focos y movimientos revolucionarios en la región o de gobiernos no alineados con los intereses geopolíticos y económicos de Estados Unidos 3 .

Si después de la Segunda Guerra Mundial se había instalado un clima de conflicto potencial con la Unión Soviética (típicamente denominado Guerra Fría), ubicando al enemigo, geopolíticamente hablando, afuera del territorio estadounidense; la Revolución Cubana condujo al gobierno estadounidense a reformular su geoestrategia y posicionar al enemigo adentro del territorio, es decir, en América Latina ${ }^{4}$.

De esta manera, dio inicio una campaña político-ideológico-militar anticomunista en la región que, incluyó desde la implementación de programas de formación militar para los aparatos castrenses locales en el Colegio Interamericano de Defensa (IADC) de Washington (Comblin, 1988), el financiamiento de guerras de baja intensidad en Centroamérica que exterminaron poblados enteros (Torres, 2013 y Kruijt, 2009) y el aniquilamiento, tortura y desaparición de grupos de oposición de cualquier tipo acusados de comunismo (Klein, 2010).

La figura del comunista como enemigo ${ }^{5}$ resulta fundamental para comprender su vínculo con Derechos Humanos, o mejor dicho, con la ausencia de éstos, pues, como Gallardo (2006) formula, a través de la pregunta de si los comunistas tienen derechos humanos, la respuesta que brinda es poderosamente ilustrativa y sugerente: "[...] la dictadura empresarial/militar [chilena] liquidaba con crueldad feroz 'comunistas', no seres humanos" (GALLARDO, 2006, p. 50).

Dado que cualquier individuo podía ser convertido en comunista, por ende, en enemigo, su condición de humanidad quedaba anulada y con ello, su posibilidad de acceso a Derechos Humanos ${ }^{6}$. Siendo éstas las condiciones políticas en las que la mayor parte de las sociedades latinoamericanas se desenvolvían, Derechos Humanos configuraba la más elemental posibilidad práctica y discursiva de las organizaciones sociales para defenderse de la represión y denunciarla.

Por esta razón, como indica Gallardo (1989), el énfasis estaba puesto en la obtención y protección de los derechos individuales, lo que demandó y generó la aparición de organizaciones, comisiones o agrupaciones en pro de la defensa de Derechos Humanos y/o de la denuncia por la violación de éstos.

\footnotetext{
3 Debe recordarse que, desde la década de los cincuenta, varios países de América del Sur contaron con gobiernos de corte reformista-progresista. El caso centroamericano en este punto es distinto, puesto que, la historia de estos países se ha caracterizado por regímenes dictatoriales amigos de la línea económico-política estadounidense desde el siglo XIX.

${ }^{4}$ Esta delimitación geográfica debe ser comprendida desde los parámetros geopolíticos promovidos por Estados Unidos desde la proclamación de la Doctrina Monroe en 1823 e ideológicamente actualizada y sedimentada a finales del siglo XIX con la noción del Destino Manifiesto.

${ }^{5}$ Su referencia latina es la de hostis. Al respecto, puede observarse las implicaciones de esta figura política elaboradas por Schmitt (2013 y 2014).

${ }^{6}$ A propósito de la supresión de la condición de humanidad de un individuo puede examinarse el excelente análisis ofrecido por Arendt (2015) en el que ilustra la condición de los apátridas y refugiados durante la Segunda Guerra Mundial. Asimismo, las reflexiones de Benjamin (2016) sobre la nuda vida y de Agamben (2013) sobre el homo sacer.
} 
Asimismo, la entrada en vigencia de los Pactos Internacionales de Derechos Civiles y Políticos y Económicos, Sociales y Culturales en 1976 y la firma de la Convención Americana sobre Derechos Humanos en 1978, representaron un importante respaldo jurídico a nivel internacional para la emergencia de estos grupos organizados; sin que ello significara en la mayoría de los casos la detención de la persecución contra estos o la obtención de desde los aparatos judiciales de cada país; por el contrario, la impunidad hasta nuestros días ha sido la tendencia predominante.

La reunión de estas condiciones propició el ingreso de Derechos Humanos a las discusiones que desde el Trabajo Social se desarrollaban en América Latina, sobre todo durante la década de los ochenta, gracias a la transición de gobiernos electoralmente establecidos, por supuesto, sin que ello significara un retroceso en la implementación del programa económico neoliberal ni la transferencia efectiva de poder hacia la población para la conformación de una democracia popular.

\section{La emergencia de Derechos Humanos en las discusiones del Trabajo Social en América Latina}

La implementación del programa neoliberal en América Latina demandó necesariamente la ejecución de medidas de represión y violencia extremas en la población. Por esta razón y ante el debilitamiento y/o extinción, en la mayor parte de la región, de los movimientos revolucionarios e intelectuales de corte marxista, Derechos Humanos se convirtió en una posibilidad para atraer respaldo internacional y denunciar los miles de crímenes perpetrados por las oligarquías nacionales y los aparatos militares de cada país, financiados por los distintos gobiernos estadounidenses.

Las distintas Escuelas y profesionales de Trabajo Social no fueron ajenas a este escenario de prácticas políticas y discusiones, lo cual se hizo notar especialmente en los cambios temáticos sustantivos generados en los distintos espacios de encuentro del gremio en América Latina durante la década de los ochenta principalmente, es decir, una vez que la mayoría de las dictaduras en América del Sur, con excepción de Chile, habían dado paso a gobiernos electoralmente establecidos.

A inicios de la década de los ochenta se desarrollaron dos seminarios latinoamericanos con una temática o motivo similar en ambos que permite evidenciar cierta continuidad entre ambos: el primero fue el X Seminario Latinoamericano de Trabajo Social celebrado en São Paulo en 1980, cuyo tema de atención fue la Política Social, como señala Ander Egg (1990), a partir de cuatro subtemas centrales: Política Social en la Seguridad Social, Desarrollo Urbano y Política Social, Salud Pública y Política Social y Desarrollo rural y Política Social. Por su parte, el XI Seminario Latinoamericano de Trabajo Social realizado en Ciudad de México en 1983, se tituló Política Social América Latina.

Sin embargo, si se revisa la reseña desarrollada por Ander Egg sobre este último, llama la atención la forma en que atacó a los principales ponentes del XI Seminario: Vicente de Paula Faleiros y Consuelo Quirós, debido a la posición que ambos presentaron en ese momento: 
Si el Trabajo Social latinoamericano no estuviese bajo la nefasta influencia del cientificismo izquierdoso, no hubiese necesitado llegar a 1983 para plantear 'las posibilidades que tiene la profesión por trabajar en relación directa a la población, e inserto dentro de los propios procesos populares' (ANDER EGG, 1990, p. 418).

Y culmina diciendo: "Este Seminario expresa un discurso interno y oficial de quienes controlan el entramado ALAETS y CELATS [... ]" (ANDER EGG, 1990, p. 418). La falacia ad hominen de Ander Egg, nos muestra tanto el carácter fragmentado del Trabajo Social en la región, ya descrito por Alayón (2005) y Netto (2005), como la todavía influencia del Movimiento de Reconceptualización a inicios de la década de los ochenta en el Trabajo Social latinoamericano, a pesar de que los regímenes de Seguridad Nacional habían desaparecido en varios países de Suramérica para ese momento y con ellos, el debilitamiento del Movimiento de Reconceptualización debido a la persecución de toda forma de conocimiento crítico ${ }^{7}$.

Sin embargo, esta permanencia puede evidenciarse también mediante la revisión de la síntesis de las conclusiones del XI Seminario publicadas por el CELATS en la revista Acción Crítica. Dicho artículo enfatizó en el papel de la educación popular como un medio de trabajo con las clases populares, tema central en el Movimiento de Reconceptualización:

\begin{abstract}
Es necesario entender que el trabajador social se ubica en la contradicción capitaltrabajo y ha sido utilizado como un instrumento de los intereses de las clases dominantes, sin embargo puede tomar una opción profesional, política, privilegiando los intereses populares lo que debe entenderse como una alianza de clases (CENTRO LATINO AMERICANO DE TRABALHO SOCIAL, 1983, p. 95).
\end{abstract}

Además, el CELATS revalorizó la experiencia revolucionaria nicaragüense y su trabajo en materia de vivienda, remarcó los problemas en el sistema de salud a causa de la deuda externa y la crisis económica y antagonizó la experiencia de educación formal y la educación popular.

De esta manera, podemos identificar, tanto en los comentarios de Ander Egg como en los del CELATS (desde posiciones antagónicas), que a inicios de la década de los ochenta en el Trabajo Social latinoamericano todavía las ideas reconceptualizadoras persistían en las discusiones y espacios de reflexión regional del gremio, especialmente por el rescate y examen que el CELATS procuró realizar en torno a las distintas situaciones de violencia que todavía se vivían en los países latinoamericanos.

Por ende, no es de extrañar que los Seminarios Latinoamericanos de Trabajo Social siguientes desarrollados en esta misma década hayan potenciado la incorporación de Derechos Humanos como tema de la agenda de reflexión del gremio, en cuanto demanda sensible de la mayor parte de la población del área.

EI XII Seminario Latinoamericano de Trabajo Social celebrado en Medellín, 1986; recuperó los ejes de trabajo: Movimientos Sociales, Educación Popular y Trabajo Social. Al revisar sus contenidos, las ponencias compiladas en el primero de los dos tomos de este Seminario,

\footnotetext{
7 Por esta razón Netto (2005) denominó al Movimiento de Reconceptualización como un movimiento inconcluso.
} 
presenta una tendencia a la crítica de la transición a "la" democracia en los diferentes países de América Latina ${ }^{8}$ de ese momento.

Por su parte, la última parte del primer tomo y la totalidad del segundo tomo, que compila las ponencias restantes de este Seminario ${ }^{9}$, se centran en recuperar las experiencias de diversos movimientos sociales en diferentes países de América Latina, en los que se incluían: movimientos feministas, de Derechos Humanos, homosexuales, ecológicos, damnificados por desastres naturales, de menores, indigenistas, obreros, urbanos, campesinos y barriales.

Aquí, las ponencias de las trabajadoras sociales María Vélez (Colombia) y Gioconda Espina (Venezuela) y de la organización Casa de la Mujer ${ }^{10}$ merecen resaltarse porque condensan tanto la crítica a los partidos tradicionales de izquierda (tendencia de este Seminario), como la incorporación de Derechos Humanos en su discurso, al resaltar el papel de la participación de las mujeres en los Comités de Defensa de Derechos Humanos en sus países.

Lo anterior es de gran importancia porque en la recepción de Derechos Humanos dentro del gremio jugó un papel importante la mediación de la discusión de género, porque, mientras las formas tradicionales de organización de la izquierda comunista (el Partido Obrero) priorizaron la clase sobre cualquier otra forma de opresión y dominación; Derechos Humanos abría la posibilidad de incorporación de esta sensibilidad, sus luchas y marcos de pensamiento.

Por otro lado, las ponencias del Equipo de Asistentes Sociales de la Comisión por el Reencuentro de los Uruguayos y de las trabajadoras sociales Gloria Lizarraga (Honduras) e Iranildes Viana (Brasil), hicieron hincapié en las distintas situaciones de violación de derechos humanos que en sus países se vivía producto de las dictaduras.

Precisamente, los escenarios de represión conjugados con la incapacidad de la denominada izquierda tradicional y la crítica a los procesos de transición promovidos por las distintas oligarquías nacionales paralelos a los procesos de amnistía generalizada que se dieron en todos los casos, abrieron el portillo a la recepción de Derechos Humanos como nueva sensibilidad ético-política; misma que se distanciaba de los valores políticos defendidos por el Movimiento de Reconceptualización basados en la liberación del hombre y la construcción del socialismo.

\footnotetext{
${ }^{8}$ Para ver los detalles puede recurrirse a mi investigación Herrera (2014).

9 Encontramos autores y autoras como: Orlando Fals Borda (Colombia), Jorge Orosio (Chile), Nidia Castillo (ALAETS), María Tobón (CELATS), Lady Fonseca (Venezuela), Hernán Vásquez (Colombia), Boris Lima (Colombia), Marco Mejía (Colombia), Nery Paz y José Rebellato (Uruguay). Me gustaría aprovechar para remarcar un cierto acento en las ponencias de Fals Borda, Lady Fonseca y Marco Mejía de distanciamiento con los partidos de izquierda comunistas y la concepción de clase social; pues en la práctica política o a nivel teórico estos no contienen la diversidad de los movimientos sociales existentes. Esto remarca la transición de un discurso con mayor influjo de cierta comprensión marxista de la realidad, hacia otro discurso con pluralidad de tópicos, entre ellos, el de Derechos Humanos.

${ }^{10}$ Cabe indicar que no es de extrañar que sean mujeres quienes coloquen con mayor énfasis la reivindicación de Derechos Humanos y la crítica a la izquierda tradicional, en cuanto, la forma de recepción del comunismo en América Latina y los Partidos Comunistas del área se caracterizó por mantener formas de organización machistas o que sobreponían el conflicto de clases como prioridad frente a la dominación patriarcal.
} 
Por supuesto, hablamos de que la experiencia de los regímenes de Seguridad Nacional en Suramérica y la Guerra de Baja Intensidad en Centroamérica marcan un antes y un después en la historia de América Latina. Mientras el Movimiento de Reconceptualización vio su surgimiento a raíz del impulso crítico y revolucionario que despertó la Revolución Cubana, la conformación de las Comunidades Eclesiales de Base influidas por la Teología Latinoamericana de la Liberación, el fortalecimiento de las guerrillas en Centroamérica, la presencia de gobiernos de corte reformista-desarrollista y el robustecimiento teórico que intelectuales como Paulo Freire, Ernesto Guevara, Marta Harnecker y Orlando Fals Borda generaron en América Latina; la década de los ochenta, por el contrario, se caracterizaba por ser el periodo que seguía a la barbarie de las dictaduras, caracterizado por la desaparición de cientos de miles de personas y la persecución, exilio o exterminio de decenas de movimientos sociales e intelectuales críticos.

En medio de esta transición, Derechos Humanos aparecía como una esperanza para sostener el impulso de justicia que muchos familiares de las víctimas y grupos organizados de la sociedad civil buscaban perseguir. Así, para el año de 1989, se celebró en Quito el XIII Seminario Latinoamericano de Trabajo Social, cuyo centro temático manifestó con total claridad el cambio de la sensibilidad política que se venía gestando a lo largo de esta década, tal como puede apreciarse en los motivos de su nombre: Democracia, Derechos Humanos y Participación en la alternativa popular.

Así, durante este Seminario, el binomio Democracia-Derechos Humanos aparece con fuerza, especialmente bajo dos líneas de reflexión bastante definidas: 1) la crítica de los acontecimientos ocurridos en América Latina enmarcados en la crisis económica internacional, la deuda externa y la represión ejecutada por los Estados de Seguridad Nacional y sus políticas de guerra total y guerra de baja intensidad ${ }^{11}$ y 2) la introducción del problema de "la" democracia formal vs la democracia representativa-participativa que apareja Derechos Humanos ${ }^{12}$.

Este dato es neurálgico porque, como he dicho ya, son las transiciones democráticas (liberales) las que generaron en casi todos los países latinoamericanos las condiciones de posibilidad de incorporación de un discurso de Derechos Humanos, el cual, como podemos observar, ingresó a la profesión por la vía de la exposición y denuncia de las situaciones de violencia y represión vividas por muchos años en nuestros países.

Ahora bien, no solamente en los Seminarios Latinoamericanos este fenómeno se presentó. La revista Acción Crítica también desempeñó un papel importante en la colocación y divulgación de este tópico y, aunque fueron pocos los artículos sobre Derechos Humanos que en su momento publicaron durante los ochenta, sí desarrollaron un enlace importante

\footnotetext{
${ }^{11}$ A propósito de esta línea se encuentran en este Seminario el Discurso Inaugural de Gladys de Borja sobre la crisis, violencia y pobreza en América Latina por las medidas impuestas por el FMI; las ponencias de Obdulio Pappa y Fabián Gonon Ortiz, ambos de Guatemala, sobre la precarización del pueblo guatemalteco y situación de violación de Derechos Humanos en su país. Asimismo, la participación del reconocido sociólogo ecuatoriano Agustín Cueva.

${ }^{12} \mathrm{Al}$ respecto, puede observarse las ponencias de Guido Bonilla (Colombia), Héctor Mondragón (Colombia), Francisco Bustamante (Uruguay), Rosario Sánchez e Ismael Quiroz (Bolivia), Xanthis Suárez (Nicaragua), José Escalante y otros (Bolivia), María de Rosa y otras (Uruguay) y las organizaciones: Inter-Religious Task Force on Central American y el Colectivo Docente de la Escuela de Trabajo Social (Nicaragua).
} 
a finales de esta década con el XIII Seminario Latinoamericano de Trabajo Social, puesto que le dedicaron dos de sus números: Participación popular, democracia y Derechos Humanos, Revista $\mathrm{N}^{\circ} 24$ en 1988 y Derechos Humanos: un reto profesional, Revista $\mathrm{N}^{\circ} 25$ en 1989.

No obstante, pocos años antes, en 1984, se había publicado una entrevista a los (as) integrantes del Colectivo de Trabajo Social de Santiago de Chile, donde señalaron:

Empezamos principalmente a pensar el Trabajo Social en el ámbito del trabajo
solidario, el trabajo no oficial, porque ese era nuestro espacio inicial, fue algo así
como nuestro espacio referente. De ahí surgieron los primeros escritos del
Colectivo, planteando el problema de los pobladores, lo urbano, el Estado, las
necesidades básicas, y nuestro rol profesional. Nos preguntamos qué había
pasado con nuestra relación de trabajadoras sociales, con la política, con los
derechos humanos; las nuevas prioridades que surgieron del curso de los
acontecimientos en la última década, qué aporta todo esto a una nueva identidad
del Trabajo Social (COLECTIVO DE TRABAJO SOCIAL DE SANTIAGO DE CHILE, 1984,
p. 11).

Dos son los elementos importantes de destacar y atender aquí. El primero es la reiterada relación de la aparición y apropiación de un discurso de Derechos Humanos en contra de las experiencias de represión nacional, esta vez, por la dictadura pinochetista específicamente.

El segundo tiene que ver con las dificultades para tratar el tema desde el ámbito profesional. Podemos en este sentido especular dos razones: 1) la dictadura en Chile no sólo fue la más represiva sino también la más duradera en América Latina, por lo que cualquier pensamiento y organización adversa al régimen podía ser exterminada y 2) la efectiva influencia del Movimiento de Reconceptualización en torno a la participación activa de trabajadores (as) sociales en organizaciones o movimientos políticos.

En todo caso, las dos razones no son excluyentes y más bien, nos permitirían entrever que el Movimiento de Reconceptualización, a pesar de nunca haber incorporado a Derechos Humanos en su agenda política, potenció su posterior recepción en específicos círculos del gremio bajo ciertas condiciones socio-históricas, lo cual explicaría también la rápida incorporación del tema en las discusiones gremiales latinoamericanas, considerando que éstas fueron una iniciativa original del Movimiento de Reconceptualización.

Ahora bien, dicha recepción mantuvo un carácter bastante claro: fue una herramienta para guiar la crítica y denuncia contra los crímenes desarrollados por los distintos regímenes de seguridad nacional en América Latina y el empobrecimiento de la mayoría de la población de la región debido a la implementación del programa neoliberal. En otras palabras, Derechos Humanos ingresó como un contenido fundamentalmente práctico-político; esto podrá verse con mayor nitidez en el próximo apartado.

De esta manera, puedo ofrecer de forma general el momento en que Derechos Humanos cobró auge en el Trabajo Social de América Latina y las razones históricas que dan respuesta a su por qué. Ahora bien, esto nos conduce a otro problema asociado: la comprensión teórica del gremio sobre Derechos Humanos. 


\section{tempordils}

HERRERA RODRÍGUEZ, OMAR SANTIAGO

\section{Una comprensión muy limitada de Derechos Humanos}

Si bien, como expuse en el apartado anterior, la incorporación de Derechos Humanos como tema de discusión gremial provino de las denuncias y críticas hacia las situaciones de represión y violencia y las consecuencias económicas del programa neoliberal; la comprensión teórica de Derechos Humanos desarrollada por el gremio, tendió más bien a restringirse a los marcos categoriales liberales, ya fuese en su versión iusnaturalista, iuspositivista o una mezcla de ambas, o, a presentarse como un valor positivo ${ }^{13}$ en contraposición con la realidad que se experimentaba en ese momento por la región.

En este sentido, es importante señalar que no hubo durante la década de los ochenta una sola contribución significativa por parte del Trabajo Social en América Latina, para la discusión sobre el fundamento (la formación social moderna y sus contradicciones constituyentes) ni las expresiones (teóricas, ideológicas) de Derechos Humanos ${ }^{14}$.

Con excepción de la ponencia de las trabajadoras sociales Sánchez y Quiroz, quienes sí efectuaron una discusión-comprensión crítica de Derechos Humanos, al encontrar la lucha de los sectores populares como parte de su fundamento y las ponencias de Guido Bonilla y Francisco Bustamente (Uruguay), quienes reprodujeron una explicación iuspositivista de Derechos Humanos, el resto de las ponencias del XIII Seminario Latinoamericano de Trabajo Social partió más bien de nociones pragmáticas y axiológicas de Derechos Humanos; es decir, epistémicamente hablando, Derechos Humanos fue posicionado por lo general como parte del conocimiento no problemático de la producción de conocimientos del gremio.

Lo anterior no es un resultado azaroso, sino más bien una característica incrustada en el Trabajo Social desde su surgimiento, pues, como ya examinó Netto (1992), esta profesión ha funcionado como un receptáculo de teorías producidas en las otras ciencias sociales, para ser operacionalizadas después en las distintas prácticas profesionales. La incorporación de Derechos Humanos prosigue la tendencia histórica de la profesión, siendo incorporada con fines eminentemente prácticos, pero sin el filtro de una discusión teórica.

Esto puede rastrearse en los trabajos publicados en la revista Acción Crítica por Pantoja (1988), Palma (1988), Sánchez (1988), Pascanan y Rozas (1990), CELATS (1990) y Valenzuela $(1989)^{15}$. Todos ellos se caracterizan por haber absorbido a Derechos Humanos como un concepto/valor deseable y positivo, para ser contrapuesto a las realidades de la región.

Para ejemplificar, puedo recurrir al siguiente fragmento del artículo de Sánchez (1988), en el que la idea que he señalado se muestra con diafanidad:

Como todos sabemos, el acercamiento del Trabajo Social a la tarea de defensa de los Derechos Humanos obedeció a la irrupción del régimen militar más que a una estrategia deliberada de la profesión. Sin embargo, ésta llegó a intervenir profesionalmente en el campo provisto de un sentido ético que se confunde con

\footnotetext{
13 Nuevamente, para un desarrollo mayor sobre este tema puede recurrirse a mi estudio Herrera (2014).

${ }^{14}$ Utilizando la conceptualización que realiza Gallardo (2009).

15 Para un abordaje más detallado de cada artículo ver Herrera (2014).
} 
sus orígenes. La valoración de la persona humana y el respeto de su dignidad, cualquiera sea su condición, provienen de las raíces mismas del Trabajo Social, de su filosofía humanista y de los principios compartidos universalmente por todas las profesionales que trabajan con personas (SÁNCHEZ, 1988, p. 44).

Efectivamente, sabemos que la introducción de Derechos Humanos a las discusiones gremiales no fue ni azarosa ni deliberada por la profesión, sino que, respondió al conjunto de condiciones socio-históricas que en ese momento generaron un clima político-discursivo respecto del cual Trabajo Social, por sus características, difícilmente podía haberse abstraído.

Pero más importante todavía es que la coligación de Derechos Humanos al gremio no se realizó por la vía de la reflexión y discusión teórica, sino, porque era más fácil establecer un nexo entre Derechos Humanos con un cierto ethos identitario del Trabajo Social, el cual ha recuperado y sigue recuperando históricamente el conjunto de valores y principios de la modernidad, bajo los cuales Derechos Humanos también fue pensado y creado.

De hecho, Faleiros (2005) demuestra cómo al iniciar la década de los noventa, los Códigos de Ética de Trabajo Social en Brasil comenzaron a incorporar Derechos Humanos, como claro ejemplo de la transición política de época, pero también, como muestra del debilitamiento del Movimiento de Reconceptualización que décadas atrás mantenía cierta hegemonía en el gremio, incluyendo la del ethos profesional, cuyo núcleo de valores provenía de cierta interpretación del marxismo.

No obstante, al articularse Derechos Humanos con valores o ideas como: democracia, justicia, solidaridad, entre otras (todas estas nociones comunes también para el Trabajo Social), su introducción y sedimentación por la vía de la identidad profesional contaba con muchísima facilidad para darse y desarrollarse.

De hecho, en 1992, el entonces presidente de la International Association of Schools of Social Work (IASSW), Ralph Garber (Canadá), indicó en las conclusiones del XXV Congreso Internacional de la IASSW, para la Nueva Declaración de la Misión de esta entidad que: "The new Mission Statement confirms a long standing commitment to social justice and human rights" (IASSW, 1992, p. 83),

Esta visión la podemos encontrar hasta nuestros días con la definición que la IASSW adoptó en el año 2014 para comprender al Trabajo Social a nivel mundial:

El trabajo social es una profesión basada en la práctica y la disciplina académica que promueve el cambio y el desarrollo social, la cohesión social y el fortalecimiento y la liberación de las personas. Principios de la justicia social, los derechos humanos, la responsabilidad colectiva y el respeto a las diversidades son fundamentales para el trabajo social. Sustentado por las teorías del trabajo social, ciencias sociales, humanidades y los conocimientos indígenas, el trabajo social involucra a las personas y estructuras para hacer frente a desafíos de la vida y mejorar el bienestar. La definición anterior se puede amplificar a nivel nacional y / o regional (IASSW, 2014).

Como puede verse, Derechos Humanos ocupa el lugar de principio-valor, lo que en realidad configura un lugar cómodo que permite evitar la discusión y comprensión de este tema, 
pero emplearlo al mismo tiempo. Esto en realidad no es un fenómeno típico de Trabajo Social, aunque como indiqué, guarda una correlación con la forma en que el gremio se ha desarrollado históricamente en torno a su relación con distintas matrices teóricas.

Por ejemplo, cuando se alcanzó la firma de la DUDH, como señala Beitz (2010), el reconocido intelectual francés Jacques Maritain, indicó: estamos de acuerdo con los derechos, pero con la condición de que nadie nos pregunte por qué. Por otro lado, el reconocido filósofo político italiano Norberto Bobbio (1991), planteó a finales del siglo XX la necesidad de dejar de discutir Derechos Humanos para únicamente dedicarse a su ejecución; es decir, una posición completamente pragmática sobre este tema.

En estas condiciones, las discusiones y propuestas de reflexiones teóricas sobre Derechos Humanos continúan al día de hoy siendo carentes o bastante deficientes desde el Trabajo Social en América Latina ${ }^{16}$, a pesar de que es un tema del que se habla con extensión y sobre el cual se obtiene a lo interno del gremio una posición políticamente aceptable con cierta facilidad.

De esta manera, la comprensión sobre Derechos Humanos que se dio en ese entonces se encuentra especialmente restringida a su comprensión como imperativo ético-político del ejercicio profesional sin mediar reflexión teórica alguna; lo cual, por supuesto, conlleva necesariamente un debilitamiento de cualquier acción política que parta de Derechos Humanos. Esto lo veremos particularmente en el caso costarricense.

\section{Recepción en el Trabajo Social costarricense de la discusión sobre Derechos Humanos}

Resulta de gran interés incluir en este artículo los principales hallazgos acerca de mi estudio sobre la recepción de Derechos Humanos en Costa Rica, con el fin de ofrecer a los (as) lectores de este trabajo un ejemplo de la tesis que he propuesto para pensar la recepción de las discusiones de Derechos Humanos en el plano nacional de desarrollo de la profesión, de modo que sirva como clave de lectura e ingreso analítico al problema.

La primera referencia sobre Derechos Humanos en una publicación de la Escuela de Trabajo Social (ETS) se presenta en el 1982, elaborada por la profesora Lorena Molina Molina; quien también desarrolló otros dos artículos sobre Derechos Humanos en los años 1989 y 1991. Ahora bien, en realidad esta primera referencia resulta ser escueta y marginal, puesto que indicó únicamente la necesidad de defender el derecho humano a opinar y participar "[... ] en la construcción de un mundo mejor" (MOLINA, 1982, p. 4).

Esto es importante de señalar porque, a nivel analítico resulta poco útil igualar la aparición de un concepto o de una idea en un documento con la emergencia de una discusión, puesto que, el primer caso puede ser un fenómeno aislado o una anomalía, mientras que, en el segundo caso existen una serie de factores y condiciones que contribuyen a posicionar y

\footnotetext{
${ }^{16}$ En este sentido, cabría destacar que en Brasil ha habido una especie de semillero de discusiones basadas principalmente en escueta y poco rigurosa reflexión del filósofo Ivo Tonet en un artículo titulado: Par alem dos dereitos humanos. Para una crítica de esta forzada lectura de Marx sobre la cuestión de Derechos Humanos, puede verse mi artículo Herrera (2017).
} 
desarrollar un campo de discusiones que son a su vez, campos de relaciones entre actores sociales que responden a su época.

Esto puede entenderse de mejor manera en el caso costarricense al mencionar que, las otras dos docentes de la ETS que en esa década desarrollaron trabajos sobre Derechos Humanos fueron Marta Odio Benito (1985, 1986 y 1987) y Laura Guzmán Stein (1991, 1992a, 1992b y 1993); es decir, el segundo lustro de esa década es determinante para ampliar la producción de conocimientos sobre Derechos Humanos. Profundizaré al respecto.

En 1981 la ETS realizó una reforma curricular que perduró hasta 1993, año en el que surgieron propiamente los cursos de Ideología, ética y Derechos Humanos que permanecen hasta el día de hoy en el currículum de la carrera. Dicha reforma, como señalan Molina y Romero (1992) y que se evidencia también en el documento de la $V$ Jornada de Evaluación de la ETS desarrollada entre diciembre de 1979 y enero de 1980, enfatizó en la construcción de los Talleres, los cuales servían para dar un hilo conductor a la formación profesional; asimismo, reivindicaba como principios axiológico-políticos la transformación social y la liberación del hombre, mismos principios que permanecen todavía en el Plan Trienal 1983-1985.

Como puede observarse, la reforma curricular de 1981 presenta el último respiro de la influencia de la segunda oleada reconceptualizadora, como la describe Villalobos (2018), que se extendió a lo largo de la década de los setenta y que reunió no sólo a una generación de docentes teóricamente mejor preparadas que las de décadas anteriores, sino también a trabajadores (as) sociales exiliados de otras partes de América Latina.

Sin embargo, a partir de 1984 se dio un importante giro ideológico-político en la Escuela de Trabajo Social, mismo que se evidencia en el documento del Plan General de Acción 19831987, ratificado en el año de 1984 por la Asamblea de la ETS y que posicionó los valores del liberalismo como corpus axiológico de la formación profesional en Costa Rica: “El proyecto académico resultante de ese proceso se fundamenta en los principios democráticos establecidos en la Constitución Política de la República de Costa Rica" (ESCUELA DE TRABAJO SOCIAL, 1984, p. 2).

Hablamos específicamente de los valores: libertad, igualdad, justicia social y solidaridad. Mismos que, como hemos visto ya, fueron los valores que también generaron el enlace identitario-axiológico entre Trabajo Social y Derechos Humanos a nivel latinoamericano.

Por supuesto, este giro radical en la ETS no es azaroso sino que responde a un momento de inflexión en distintos niveles sociales.

El primero de ellos responde al cambio en la política del gobierno costarricense respecto de los organismos financieros internacionales, pues, durante la administración de Rodrigo Carazo Odio (1978-1982) el país atravesó una fuerte crisis económica producida por el distanciamiento de éste respecto de las demandas e intentos de imposición del programa neoliberal en Costa Rica; por el contrario, la administración de Luis Alberto Monge (19821986) no sólo comenzó con la implementación del primer Programa de Ajuste Estructural, sino que también, incentivó acciones fuertemente anticomunistas como la autorización a 


\section{temporalis}

la Contra nicaragüense de instalarse al norte del territorio nacional y mantuvo relaciones estrechas con la administración de Ronald Reagan.

Precisamente, fue la administración de Luis Alberto Monge la que generó las bases para la participación activa del gobierno sucesor (administración Arias Sánchez 1986-1990), en la pacificación de la región centroamericana, la desmovilización de los principales movimientos revolucionarios de la región y la extensión de amnistías generalizadas a partir de los Acuerdos de Esquipulas, que han garantizado hasta el día de hoy la impunidad de las principales figuras económicas, políticas y militares que conformaron regímenes genocidas durante los años setentas y ochentas ${ }^{17}$.

De esta manera, las condiciones sociales generales que se vivían en Costa Rica propiciaban una atmósfera marcadamente anticomunista y de respaldo ideológico para la implementación del programa económico-político neoliberal, con las facilidades de que: 1) en Costa Rica no había movimientos sociales fuertes en la década de los ochenta, 2) era innecesario implementar un régimen dictatorial ante la falta de resistencia popular y 3) la crisis económica generada por el gobierno estadounidense y los organismos financieros internacionales a finales de la década de los setenta generó un fuerte shock en la mayor parte de la población costarricense que sirvió de base psicológica para la ejecución de estas medidas presentadas como solución a la crisis.

Estos cambios en el contexto nacional deben ser entendidos en un nivel más general de la realidad, movido por los cambios en la estrategia geopolítica estadounidense hacia la región centroamericana, puesto que, Costa Rica ocupaba un lugar central para la desestabilización de los movimientos revolucionarios del área que la administración republicana de Ronald Reagan necesitaba, a diferencia de sus antecesores demócratas.

Nuevamente, Trabajo Social no escapa ni se abstrae de la dinámica mundial, regional y nacional en la que se encuentra inscrito, sino todo lo contrario. Como indiqué, en 1984 hay un cambio radical en la Dirección de la Escuela de Trabajo Social, asumiendo en lugar de la profesora Laura Guzmán Stein (hasta ese momento figura del Movimiento de Reconceptualización en Costa Rica), el profesor Luis A. Valverde Obando quien retrajo a la carrera una formación marcadamente conservadora y sostenida en los marcos axiológicos del liberalismo antes expuestos, como lo ha demostrado Villegas (2016), en su trabajo sobre las concepciones de ética que han imperado en la formación académica de la ETS.

Asimismo, en el periodo siguiente, asume la Dirección de la ETS la Lic. Florisabel Ramírez Lizano, abierta simpatizante del Partido Liberación Nacional, en ese momento al mando del gobierno de Costa Rica.

El conjunto de estos procesos internacionales, nacionales e internos a la ETS potenció la reconfiguración de fuerzas dentro de la Escuela, extinguiendo casi por completo la herencia del Movimiento Reconceptualizador en la formación de trabajadores (as) sociales en el país en el marco de esta década. Para los años noventa, esto degeneraría en una formación marcadamente tecnocrática.

\footnotetext{
17 Al respecto del papel de Costa Rica durante la década de los ochenta en el conflicto armado en Centroamérica pueden verse los eruditos estudios de Chomsky 1999 y 2003.
} 
Ahora bien, a diferencia de las discusiones de Trabajo Social a nivel latinoamericano, en las que Derechos Humanos servía como principio axiológico y político para criticar las situaciones de violencia y explotación que se vivía en la mayor parte de los países; la particularidad de Costa Rica de no haber atravesado en esa época por ningún régimen dictatorial fue la incapacidad de articular la comprensión que se hizo de Derechos Humanos con los múltiples movimientos y realidades de resistencia y denuncia regional; esta limitación puede observarse en los trabajos que indiqué atrás elaborados por Odio, Molina y Guzmán.

Sin embargo, por otro lado, la comprensión teórica de Derechos Humanos en Costa Rica fue igual de limitada que la del resto del Trabajo Social latinoamericano ${ }^{18}$; adoptando principalmente tres vertientes.

La primera consistió en una concepción axiológica, la cual se encuentra en los trabajos de Molina y Smith (1989), Molina (1991 y 1993) y Guzmán y Richie (1991), quienes centraron su atención en la formación de actitudes/valores del estudiantado a partir de una educación basada en Derechos Humanos. Veamos un ejemplo:

\begin{abstract}
La tarea de construir y fortalecer la democracia es la tarea de promoción y defensa de los derechos humanos, esto es un aspecto medular en la tarea educativa, pues, es la práctica pedagógica, la cotidianidad de la vida en la escuela el principal escenario en la enseñanza-aprendizaje de y para los derechos humanos (MOLINA, 1991, p. 32).
\end{abstract}

Una vez más, Democracia-Derechos Humanos es el binomio que condensa la sensibilidad política de época demarcada por los procesos de transición a regímenes electoralmente establecidos, pero ahora, haciendo énfasis en la necesidad de que la práctica pedagógica (académica, universitaria) sea el primer foco de aprendizaje de y para Derechos Humanos; donde el para expresa la enseñanza práctico-axiológica de Derechos Humanos.

Lo anterior puede apreciarse también en el trabajo de Guzmán y Richie (1991) y Guzmán (1992b):

Los códigos de ética que orientan el ejercicio profesional en todo el Continente establecen directrices semejantes centradas en el respeto a la individualización y autodeterminación de la persona, confidencialidad, respeto a la diversidad y a las diferencias, uso disciplinado de la relación profesional, y compromiso con la democracia, la justicia social, la igualdad y la equidad (GUZMÁN; RITCHIE, 1991, 1). ${ }^{19}$

Precisamente, como he mencionado con anterioridad, esta comprensión es la que permite construir un enlace lógico, basado en el principio de semejanza, entre Trabajo Social y Derechos Humanos:

Desde sus orígenes la preocupación esencial de la profesión ha estado centrada en el mejoramiento de la condiciones de vida de los usuarios de los servicios

\footnotetext{
${ }^{18} \mathrm{Al}$ respecto, puede verse en Herrera (2014) que la ETS participó activamente de distintos Encuentros, Seminarios y Congresos regionales de Trabajo Social durante esta década.

${ }^{19}$ Esta opinión refuerza la de Faleiros (2005).
} 
sociales otorgados por instituciones estatales y organismos no gubernamentales. Precisamente por tener este amplio espacio de intervención el Trabajo Social está presente en la atención a múltiples problemáticas (trabajo, vivienda, salud, educación, capacitación) expresada en grupos humanos cuyos criterios de clasificación son diversos. En la atención de los diversos problemas, la intervención profesional del Trabajo Social está intrínsecamente articulada a los derechos humanos y con mayor asidero lo ha estado con los derechos consignados en la denominada Il Generación o sea en los derechos económicos y sociales (MOLINA; SMITH, 1989, p. 14).

Esta misma posición, pero con mayor claridad, puede verse en Guzmán (1992b): “Los principios de trabajo social se apoyan en principios fundamentales de derechos humanos de respeto a la dignidad de la persona" (GUZMÁN, 1992b, p. 7). Por supuesto, esta supuesta semejanza reproducida por las autoras, debió partir de un imaginario axiológico de la profesión: su preocupación por mejorar condiciones de vida de la población o la idea de que esta profesión inherentemente se basa en el respeto a la dignidad humana ${ }^{20}$.

A partir de esta mirada bondadosa del Trabajo Social se constituye un ligamen con Derechos Humanos, los cuales son, ad portas, un valor necesario de realizar. De esta manera, las autoras evitan dar explicaciones históricas que den cuenta de las determinaciones reales que propiciaron la emergencia e incorporación de las discusiones sobre Derechos Humanos en Costa Rica.

La segunda vertiente estuvo marcada por la recepción de Derechos Humanos a través de una matriz iuspositivista, como puede observarse en los trabajos de Odio (1985, 1986 y 1987). De hecho, ella brinda una definición de Derechos Humanos en la que se evidencia su forma de comprenderlos: "son aquellos que han sido creados o reconocidos por una autoridad pública, elevados al rango de precepto de cumplimiento inexorable y su violación implica efectos jurídicos que no están sujetos a derogabilidad arbitraria” (ODIO, 1986, p. 2)

La tercera veta, es de carácter propiamente iusnaturalista, la cual se encuentra representada en los trabajos de Guzmán (1992a y 1993). Por ejemplo:

Los llamados derechos de las mujeres se fundan en el principio de igualdad y propugna por la eliminación de toda forma de discriminación y violencia contra la mujer. Este principio subyace en la noción de derechos humanos, que plantea como postulado central que Todas las personas son iguales en derechos por su condición de Personas (GUZMÁN, 1992a, p. 2).

La idea de una condición natural de igualdad es propia del imaginario constitutivo de la modernidad y ahora, es trasladada a Derechos Humanos para defender una causa específica: la situación de desigualdad que atraviesan las mujeres. Habría que hacer notar una vez más que, el tema de género asociado a Derechos Humanos, al igual que en las discusiones latinoamericanas, vuelve a aparecer en Costa Rica; sin embargo, todavía es necesario desarrollar un estudio más específico y profundo sobre la relación histórica entre ambos temas en Trabajo Social.

\footnotetext{
${ }^{20}$ A estas alturas de la discusión sobre el surgimiento del Trabajo Social no interesa alargar esta discusión. Puede observarse la referencia a Netto (1992) y los múltiples trabajos que se han desprendido del autodenominado Servicio Social Crítico en Brasil.
} 
Ahora bien, esta forma de comprender Derechos Humanos por parte de las trabajadoras sociales que colocaron el tema y produjeron conocimiento al respecto responde no sólo a las condiciones históricas que influyeron en la ETS, sino también, a la formación que todas ellas tuvieron en el tema, la cual estuvo mediada por las posibilidades históricas de esa época ${ }^{21}$.

Así, por ejemplo, Marta Odio además de realizar estudios en Trabajo Social lo hizo también en Derecho en la Universidad de Costa Rica, asimismo, es hermana de la reconocida jurista Elizabeth Odio Benito, actual jueza de la Corte Interamericana de Derechos Humanos. De ahí que, el marco categorial iuspositivista con que piensa Derechos Humanos es en realidad una consecuencia casi evidente de su formación académica.

Por otra parte, Laura Guzmán tuvo un importante distanciamiento de la ETS a partir de 1984, época en que dejó el cargo de Dirección como mencioné páginas atrás, y mantuvo durante el segundo lustro de la década de los ochenta un importante acercamiento con el Instituto Interamericano de Derechos Humanos, el cual, históricamente ha tendido a reproducir una lectura iusnaturalista de Derechos Humanos o una lectura que procura conciliar iusnaturalismo con iuspositivsmo.

Finalmente, Lorena Molina desempeñó un papel activo en las discusiones internacionales de Trabajo Social, de ahí la semejanza con la concepción axiológica de Derechos Humanos y su interés por incorporarlos en los contenidos de currículum académico de la ETS. De hecho, ella participó en el Vigésimo-quinto Congreso Internacional de Escuelas de Trabajo Social, ya mencionado, por lo que es posible detectar las coincidencias entre sus artículos de 1991 y 1992 con la posición asumida a nivel internacional por Trabajo Social sobre Derechos Humanos.

Lo llamativo es que, estas tres trabajadoras sociales formaban parte del bando opositor a la línea hegemónica de la ETS que había ganado la Dirección en 1984 (por ejemplo, como hice notar, Laura Guzmán fue una de las principales precursoras de la segunda oleada del Movimiento de Reconceptualización en el país); sin embargo, el abandono de categorías fundamentales del marxismo, en un marco socio-histórico desfavorable para el pensamiento marxista en América Latina y especialmente en Costa Rica, generó un terreno fecundo para la incorporación de Derechos Humanos bajo una compresión fundamentalmente conservadora y liberal, pero que, si se consideran los actores en la escena inmediata, se torna como progresista.

De hecho, esto último se podría decir también de la forma de recepción de Derechos Humanos en el debate del gremio en América Latina, ya que, al lado de los desastres provocados por las dictaduras y el programa neoliberal, esta posición podía pensarse y percibirse como progresista, aunque en su núcleo fuese conservadora y profundamente limitada teóricamente.

\footnotetext{
${ }^{21}$ Esto porque, pensar Derechos Humanos desde estas tres vertientes en realidad es el mainstream con los principales Institutos e intelectuales en la materia han pensado el tema.
} 
Por otro lado, el Colegio de Trabajadores Sociales de Costa Rica (COLTRAS), no proveyó ningún avance significativo sobre lo recién dicho. A pesar de que el 31 de mayo de 1991 la Comisión para la Defensa de los Derechos Humanos en Centroamérica (CODEHUCA) y la Coordinadora Regional de Organizaciones Profesionales de Trabajo Social de México, Centroamérica y el Caribe realizaron un Seminario-Taller sobre Derechos Humanos, la comprensión que se divulgó sobre éstos se inscribió dentro de los márgenes del iuspositivismo:

\begin{abstract}
A nivel histórico los Derechos Humanos también tienen un proceso y van a aparecer los Derechos Civiles y Políticos combinados con los Derechos de los Pueblos en los primeros instrumentos que se dieron en el proceso histórico de la humanidad, en la conquista de los derechos, en el proceso que se ha vivido a veces muy fuertemente a veces por garantizar condiciones de coexistencia pacífica en las sociedades (CODEHUCA, 1991, p. 15).
\end{abstract}

Esto muestra cómo también las organizaciones o comisiones dedicadas a la denuncia de violaciones de Derechos Humanos y la promoción y protección de éstos no necesariamente poseían una comprensión profunda y crítica de Derechos Humanos; esto por el carácter pragmático de sus funciones por lo general e inclusive, las limitaciones económicas con las que debían trabajar.

En todo caso, los contenidos impartidos en el Seminario-Taller no tuvieron ninguna repercusión en el modo en que el gremio asumió Derechos Humanos, lo cual puede corroborarse en el Código de Ética que se creó en 1991, en cuya introducción se señala:

Todos los seres humanos nacen libres e iguales en dignidad y derechos, dotados como estamos de razón y conciencia, debemos comportarnos fraternal y solidariamente los unos con los otros.

Es así como el Trabajador Social, consciente de su papel dentro de la sociedad costarricense, fundamenta su desempeño profesional en los principios establecidos en la Constitución Política de nuestro país: libertad, igualdad, solidaridad y justicia social. (COLEGIO DE TRABAJADORES SOCIALES, 1991, p. 1).

Una vez más, se entremezcla el relato identitario de los valores fundamentales del Trabajo Social y el argumento iusnaturalista de la existencia de una naturaleza humana propio del pensamiento político moderno del siglo XVII, mediante los cuales se establece un nexo entre la profesión y Derechos Humanos. Por supuesto, las implicaciones de este tipo de lecturas liberales conducen a una (des)comprensión de Derechos Humanos en la medida que prescinden de su explicación socio-histórica y en consecuencia, limitan su práctica política por la adopción de principios metafísicos que chocan frente a frente con la realidad.

De esta manera, es posible señalar finalmente que, tanto en la ETS como en el COLTRAS la discusión teórica sobre Derechos Humanos fue limitada por un lado, pero también, sostenida bajo premisas liberales y conservadoras, lo cual es un reflejo de las condiciones socio-históricas de época que, como he demostrado, repercutieron también en las discusiones que sobre el tema se realizaron a nivel latinoamericano.

\title{
Conclusiones
}


He demostrado que la discusión sobre Derechos Humanos en el Trabajo Social latinoamericano y específicamente en el caso costarricense, emerge y se desarrolla durante la década de los ochenta debido a los escenarios de violencia, represión y pauperización generados por la implementación de regímenes de Seguridad Nacional y el programa económico-político neoliberal en la década anterior.

Bajo estas coordenadas, Derechos Humanos es captado por el gremio como un valor o principio con capacidad de nutrir una posición política crítica frente a las realidades que en ese momento vivía la mayor parte de los países latinoamericanos. Sin embargo, esto no conllevó que hubiera una discusión teórica acerca de su fundamento; de modo que, la recepción del tema cobró un carácter predominantemente pragmático y axiológico.

Asimismo, por este carácter, se tendió a establecer una relación inherente entre una supuesta identidad de Trabajo Social (basada en principios abstractos como democracia, justicia social, igualdad, etc.) y Derechos Humanos, esquivando con ello la necesidad de comprender los motivos socio-históricos que en realidad habían generado dicha articulación en un momento y bajo condiciones específicas.

Por otro lado, a pesar de que Costa Rica no atravesó por ninguna dictadura en esta época, la política anticomunista y neoliberal asumida por los gobiernos de esa época generó las condiciones socio-históricas necesarias para hacer retroceder el avance de la recepción de las ideas reconceptualizadoras en el Trabajo Social costarricense. A cambio, la ETS experimentó un fuerte retroceso conservador a nivel teórico y una apertura ideológicopolítica hacia una específica comprensión de Derechos Humanos, determinada (al igual que en el resto de la profesión en América Latina) por las matrices iusnaturalista e iuspositivista y por una reducción axiológica sobre la cuestión.

De esta manera, si bien las condiciones históricas particulares del caso costarricense proveen una serie de características locales, no inhiben los contenidos centrales de la tesis explicativa que propongo para pensar la emergencia y desarrollo de la discusión sobre Derechos Humanos, sino que, la enriquecen a través de su concreción en un nivel más local de análisis.

\section{Referencia}

AGAMBEN, G. Homo sacer: el poder soberano y la nuda vida. Valencia: Pretextos, 2013.

ALAYÓN, N. El Movimiento de Reconceptualización. Una mirada crítica. En: ALAYÓN, N. (Org.). Trabajo Social Latinoamericano: a 40 años de la reconceptualización. Buenos Aires: Espacio, 2005. p. 09-17.

ANDER EGG, E. Historia del Trabajo Social. Buenos Aires: Hvmanitas, 1990.

ARENDT, H. Los orígenes del totalitarismo. Madrid: Alianza, 2015.

BEITZ, C. La idea de los derechos humanos. Madrid: Ediciones Jurídicas y Sociales, 2010. 
BENJAMIN, W. Hacia la crítica de la violencia. En: TIEDEMANN, R.; SCHWEPPENHÄUSSER, H. (Ed.). Walter Benjamin. Obras. Libro II/vol. 1. 3ra ed. Madrid: Abada, 2016. p. 183-205.

BOBBIO, Norberto. El tiempo de los derechos. Madrid: Editorial Sistema, 1991.

CENTRO LATINOAMERICANO DE TRABAJO SOCIAL. En: SEMINARIO LATINOAMERICANO DE TRABAJO SOCIAL, 12., Medellín-Colombia, 1986. Anales... Lima: Nuevos Cuadernos CELATS, 1987.

CENTRO LATINOAMERICANO DE TRABAJO SOCIAL. En: CONGRESO INTERNACIONAL DE LA IASSW, 25. Revista Acción Crítica, Lima, n. 28, p. 5-16, dic. 1990.

COLEGIO DE TRABAJADORES SOCIALES DE COSTA RICA. Código de ética. 1991. Disponible en: <http://www.trabajosocial.or.cr/pagina/?id=19\&mid=108>. Acceso en: 29 sep. 2018.

COMISIÓN PARA LA DEFENSA DE LOS DERECHOS HUMANOS EN CENTROAMÉRICA. En: SEMINARIO-TALLER SOBRE DERECHOS HUMANOS, San José, 31 mayo 1991.

CHOMSKY, Noam. La quinta libertad: la intervención de los Estados Unidos en América Central y la lucha por la paz. Barcelona: Crítica, 1999.

CHOMSKY, Noam. La cultura del terrorismo. Madrid: Editorial Popular, 2003.

COLECTIVO DE TRABAJO SOCIAL DE SANTIAGO DE CHILE. En busca de la identidad. Revista Acción Crítica, Lima, n. 15, p 9-12, jul. 1984.

COMBLIN, J. Doctrina de Seguridad Nacional II. San José: Editorial Nueva Década, 1989.

COMBLIN, J. Doctrina de Seguridad Nacional I. San José: Editorial Nueva Década, 1988.

CONSEJO DE TRABAJO SOCIAL. “Memoria del III Congreso Nacional de Trabajo Social. Teoría y Práctica del Trabajo Social para el Desarrollo". Celebrado del 23 al 25 de octubre, San José, 1991.

CONSEJO DE TRABAJO SOCIAL. Memoria del I Congreso Nacional de Trabajo Social. "Estrategias de Intervención de Trabajo Social con proyección para el año 2000". Celebrado del 18 al 22 de noviembre. San José, 1985.

ESCUELA DE TRABAJO SOCIAL. V jornada de evaluación. Diciembre 1979-Enero 1980. San José, Archivo de la Universidad de Costa Rica. Caja 10440. Tomo 1058.

ESCUELA DE TRABAJO SOCIAL. Plan Trienal de la Escuela de Trabajo Social 1983-1985. San José, Archivo de la Universidad de Costa Rica. 1983. Caja 10439. Tomo 1056.

ESCUELA DE TRABAJO SOCIAL. Plan General de Acción 1983-1987. San José. Archivo de la Universidad de Costa Rica, 1984. Caja 10438. 
FELEIROS, V. Reconceptualización del Trabajo Social en Brasil: ¿una cuestión en movimiento?. En: ALAYÓN, N. (Org.). Trabajo Social Latinoamericano: a 40 años de la Reconceptualización. Buenos Aires: Espacio, 2005. p. 57-70.

GALLARDO, H. Teoría crítica: matriz y posibilidad de Derechos Humanos. Murcia: David Sánchez Rubio, 2008.

GALLARDO, H. Derechos Humanos como movimiento social. Bogotá: Desde Abajo, 2006.

GALLARDO, H. Elementos de política en América Latina. San José: Departamento Ecuménico de Investigaciones, 1989.

GUZMÁN, L. Elementos conceptuales y metodológicos para la investigación de derechos humanos con perspectiva de género. 1993. Disponible en:

<http://www.ts.ucr.ac.cr/bv/prodoc.php>. Acceso en: 10 jul. 2013.

GUZMÁN, L. La paz y los Derechos Humanos en las vidas de las mujeres: rompiendo silencios abriendo nuevos cambios. 1992a. Disponible en:

<http://www.ts.ucr.ac.cr/bv/prodoc.php>. Acceso en: 10 jul. 2013.

GUZMÁN, L. Tipología sobre violaciones a los Derechos Humanos contra la mujer por su condición de mujer. 1992b. Disponible en: <http://www.ts.ucr.ac.cr/bv/prodoc.php >. Acceso en: 10 jul. 2013.

GUZMÁN, L.; RITCHIE, D. Los Derechos Humanos en la enseñanza del Trabajo Social: avances, problemas y desafíos frente a una sociedad en cambio. 1991. Disponible en: $<$ http://www.ts.ucr.ac.cr/bv/prodoc.php $>$. Acceso en: 10 jul. 2013.

HERRERA, O. ¿Quién es el sujeto de Derechos Humanos? Discusión entre marxismo y posfundacionalismo. Revista Praxis, Heredia, n. 76, p. 75-89, jul./dic. 2017.

HERRERA, O. Trabajo Social: Formación académica y Derechos Humanos. 2014. Tesis (Trabajo Social)-Universidad de Costa Rica, San José, 2014.

HINKELAMMERT, F. Lo indispensable es inútil: hacia una espiritualidad de la liberación. San José: Editorial Arlekin, 2010.

INTERNATIONAL ASSOCIATION OF SCHOOLS OF SOCIAL WORK. En: INTERNATIONAL CONGRESS OF SCHOOLS OF SOCIAL WORK, 25., 1990. Anales... IASSW, 1992.

INTERNATIONAL ASSOCIATION OF SCHOOLS OF SOCIAL WORK. Definición de Trabajo Social Mundial. Disponible en: <https://www.ifsw.org/what-is-social-work/globaldefinition-of-social-work/>. Acceso en: 19 sep. 2018.

KLEIN, N. La Doctrina del Shock. El auge del capitalismo del desastre. 1era ed. Madrid: Paidós, 2010. 
KRUIJT, D. Guerrilla: guerra y paz en Centroamérica. 1era ed. Ciudad de Guatemala: F\&G editores, 2009.

MOLINA, L. Enseñanza-aprendizaje de los Derechos Humanos en las Escuelas de Trabajo Social. Revista Costarricense de Trabajo Social, San José, n. 1, p. 30-36, 1991.

MOLINA, L. Movimientos sociales y urbanos. San José: Archivo de la Universidad de Costa Rica, 1982. Caja 10440. Tomo 1058. 1982.

MOLINA, L.; ROMERO, M. El desarrollo curricular de la Escuela de Trabajo Social (19421991). Revista de Ciencias Sociales, San José, n. 56, p. 63-78, 1992.

MOLINA, L.; SMITH, M. Trabajo Social en la atención a refugiados centroamericanos en Costa Rica. 1989. Disponible en: <http://www.ts.ucr.ac.cr/binarios/docente/pd000251.pdf $>$. Acceso en: 10 jul. 2013.

NETTO, J. A Reconceituação: ainda via, 40 anos depois. Feleiros, V. Reconceptualización del Trabajo Social en Brasil: ¿una cuestión en movimiento?. En: ALAYÓN, N. (Org.). Trabajo Social Latinoamericano: 40 años de la reconceptualización. 1ra ed. Buenos Aires: Espacio, 2005, p. 71-84.

NETTO, J. Capitalismo monopolista y servicio social. São Paulo: Cortez, 1992.

ODIO, M. El Refugiado Centroamericano en Costa Rica. San José: Universidad de Costa Rica, 1987. Disponible en: http://www.ts.ucr.ac.cr/bv/prodoc.php. Acceso en: 10 jul. 2013.

ODIO, M. Los Derechos Humanos en el ordenamiento jurídico costarricense. 1986. Disponible en: <http://www.ts.ucr.ac.cr/bv/prodoc.php>. Acceso en: 10 jul. 2013.

ODIO, M. Relación entre los principios de sustentación orgánica de la carta de los Estados Americanos y los deberes y derechos fundamentales de los Estados miembros. 1985. Disponible en: <http://www.ts.ucr.ac.cr/bv/prodoc.php>. Acceso en: 10 jul. 2013.

PANTOJA, G. Derechos Humanos y políticas sociales. Revista Acción Crítica, Lima, n. 23, p. 17-30, ago. 1988.

PALMA, D. Las tareas de la construcción democrática. Revista Acción Crítica, Lima, n. 24, p. 31-42, dic. 1988.

PASCANAN, C.; ROZAS, M. (1990). Algunas reflexiones sobre la Conferencia Mundial de Trabajadores Sociales. Revista Acción Crítica, Lima, n. 28, p. 5-16, n. 28, dic. 1990.

SÁNCHEZ, D. Trabajo Social en Derechos Humanos. Revista Acción Crítica, Lima, n. 24, p. 43-50, dic. 1988.

SCHMITT, C. El concepto de lo político. 2da ed. Madrid: Alianza, 2014. 
SCHMITT, C. Teoría del partisano: acotación al concepto de lo político. 6ta ed. Madrid: Trotta, 2013.

TONET, I. Para além dos direitos humanos. Revista Novos Rumos, São Paulo, n. 37, p. 6372, 2002.

TORRES, E. Revoluciones sin cambios revolucionarios. 2da ed. Ciudad de Guatemala: F\&G editores, 2013.

UNIVERSIDAD CENTRAL DE VENEZUELA; ASOCIACIÓN VENEZOLANA DE ESCUELAS DE TRABAJO SOCIAL. En: SEMINARIO LATINOAMERICANO DE TRABAJO SOCIAL.

DEMOCRACIA, DERECHOS HUMANOS Y PARTICIPACIÓN EN LA ALTERNATIVA POPULAR, 13., Quito, 1989. Anales... Quito: FACES/UCV; ALAETS/CELATS, 1990.

VALENZUELA, J. Seminario Regional Andino. Revista Acción Crítica, Lima, n. 25, p. 53-56, jun. 1989.

VILLALOBOS, M. Reconceptualización a la tica: apuntes históricos para el Trabajo Social costarricense. Revista de Ciencias Sociales, San José, n. 159, p. 57-71, 2018.

VILLEGAS, C. Trabajo Social y conservadurismo ético-político: un análisis del discurso ético profesional en Costa Rica. Revista Conceptos, Buenos Aires, n. 498, 2016. 